\title{
Circumstances and their Roles in the Development of Editorials
}

\author{
Olusegun O. Jegede \\ Department of English and Literary Studies, Lead City University, Ibadan \\ Correspondence: E-mail: jegedeolusegun@yahoo.com \\ Received: August 1, 2018 \\ Accepted: September 10, 2018 Online Published: September 12, 2018 \\ doi:10.5430/wjel.v8n2p21 \\ URL: https://doi.org/10.5430/wjel.v8n2p21
}

\begin{abstract}
The study identified and categorised the features of the circumstantial options in the selected newspaper editorials and interpreted the content expressed by the options. The options were then compared to the opinions expressed in the text. These were done with a view to investigating the roles played by circumstances in the development of editorials. Data for the study were elicited from newspapers. Seven editorials were purposively selected from the 28 editorials collected. The selected editorials cut across different aspects of life, including safety and security, crime, politics, economics and religion. Each editorial was broken down into sentences, but only the main clauses in the sentences were analysed. The findings revealed that some circumstantial options were prominent in the texts. These included location, manner, extent and cause. They also revealed that with circumstances in editorials, editorials can help to articulate a better understanding of the news media, the unique handling of language and text, and the impact on thought and culture. The study concluded that the experiential meta-function in systemic functional linguistics helped to highlight the features of editorials.
\end{abstract}

Keywords: Editorials, Language, Systemic Functional Linguistics, Ideational Metafunction

\section{Introduction}

Editorials express the ideological outlook of a news organization, try to make sense of current events for their reading public, and advise the authorities. Editorials are also a form of public discourse, which reproduce existent opinions, values, ideologies, and power structures (Shokouhi and Amin, 2010). To study media is to study society. However, media are not just passive agents; they also have an active role, and shape perspectives, making them independent sources of opinion.

Editorials are forums for the articulation of multiple ideas, promoting public debate on important issues (Flowerdew and Dudley-Evans, 2002). According to Fartousi (2012), editorials can be defined as the space in which newspapers voice their opinions about the most pressing issues facing the country. Their role is to persuade readers and the government, in particular, to not only understand a particular viewpoint, but to also make that view a reality.

Additionally, editorials are written by an unnamed team of editors. In spite of having multiple writers, the paper usually holds consistent views about particular topics. Therefore, the reader can expect the newspaper's stance on a variety of subjects such as terrorism, religion, or the government. Editorials are very rich in language, context and rhetoric (Duyile, 2005). These make it a useful source of data for linguists. The following section presents some of the studies that have been carried out in editorials from different perspectives.

\section{Theoretical Concepts of SFL}

\subsection{Systemic Functional Linguistics}

Systemic Functional Linguistics (SFL) is an approach to linguistics that considers language as a system. It was developed by Michael Halliday. Halliday incorporates two central dimensions of language. The term 'systemic' foregrounds Saussure's paradigmatic axis' in understanding how language works. In other words, for Halliday, a central theoretical principle is that any act of communication involves choices on many scales. The choices can be mapped using the representation tool of the 'system network'. In addition, his linguistics is termed 'functional', because it has evolved in the service of 'certain functions' that have left their mark on the structure and organisation of language.

Thus, Halliday (1985) notes that the term systemic refers to the view of language as "a network of systems, or interrelated sets of options for making meaning". The term functional refers to Halliday's view that language is as it 
is because of what it has evolved to do. In other words, SFL is the study of the relationship between language and its functions in social settings. Systemic Functional Linguistics treats grammar as a meaning-making resource and insists on the interrelation of form and meaning.

Thompson, (1994) observes that Systemic Functional Linguistics is a study of functions and semantics which is claimed to be the basis of human language and communicative activity. As opposed to structural approaches that focus primarily on syntax, SFL-oriented linguists begin with an exploration into social contexts and move on from there to look at how language acts upon, and is constrained and influenced by this social context. Halliday (2003) also describes grammar as systems and not as rules on the basis that every grammatical structure involves a choice from a describable set of options. Language is thus a meaning potential. Grammarians in SF tradition use system networks to map the available options in a language.

\subsubsection{The Metafunctions}

Halliday (1994) refers to his functions of language as metafunctions. He proposes three general functions: the ideational, the interpersonal and the textual. Each of the three metafunctions is about a different aspect of the world, and is concerned with a different mode of meaning of clauses. For the purpose of this study, the ideational metafunction will be discussed.

\section{The Ideational Metafunction}

The ideational metafunction is about the natural world in the broadest sense, including our own consciousness, and is concerned with clauses as representations (Eggins, 2004, Halliday, 1994). The ideational metafunction is the function for construing human experience. It is the means by which we make sense of "reality". Halliday (1994) divides the ideational function into two functions: the logical and the experiential metafunctions. The logical metafunction refers to the grammatical resources for building up grammatical units into complexes, for instance, for combining two or more clauses into a clause complex. The experiential function refers to the grammatical resources involved in construing the flux of experience through the unit of the clause. This study is focusing on the experiential function alone as presented by Eggins (2004).

According to Eggins (2004), the experiential metafunction, also called 'Clause as Representation', is the clause that represents the 'content' of our experiences, answering the question 'Who does what to whom'. This metafunction uses the grammatical system of transitivity. Although sharing the traditional view of transitivity that the focus is on the verb group (the Process), the system describes the whole clause (Thompson, 1994) and does not use the labels 'subject', 'verb' and 'object', seeing that 'verb' is a word class, while 'Subject' is a functional term. Instead, different functional labels are given to Participants (realised by nominal groups), Processes (realised by verbal groups) and Circumstances (realised by prepositional phrases or adverbials signifying time, place or manner) of each process type.

Halliday (1994) calls the function 'experiential' in that it is concerned with the clause in its experiential function, its guise as a way of representing patterns of experience. Language enables human beings to build a mental picture of reality, to make sense of what goes on around them and inside them (p. 106). This is the function of language with which we represent the world to ourselves and others, with which we reflect our experience of the world, with which we construct ideas about the world. Thus: representational, experiential, ideational meaning.

This function of language takes us to the heart of the status of language as 'social semiotic', a cornerstone of Halliday's theory. While the textual and interpersonal functions of language are also deeply implicated in how language creates social meanings, it is probably easiest for us to see this power of language in the experiential function. As Halliday (1994) says, it is what ordinary people (non-linguists) usually have in mind when they say something about what a piece of language 'means' (the idea of the world or some part of it represented in that piece of language).

There are three basic elements to all process structures - the process itself, the participants in the process, and the circumstances associated with the process. Halliday (1994) distinguishes six process types:

1) Material (i.e., what is going on outside oneself)

2) Mental (i.e., inner experience - awareness of our own states of being and reaction to our outer experience)

3) Relational (i.e., classifying and identifying one experience with other experiences).

4) Verbal (i.e., symbolic relationships are recognized and constructed in human consciousness)

5) Behavioural (i.e., expressing of inner workings) 
6) Existential (i.e., phenomena are recognized to exist or to happen)

The process type, according to Eggins (2004), is what underlies the differences in a paradigm, such as:

1) Diana gave some blood. [Material]

2) Diana thought she should give blood. [Mental]

3) Diana said that giving blood is easy. [Verbal]

4) Diana dreamt of giving blood. [Behavioural]

5) There is a reward for giving blood. [Existential]

6) Diana is a blood donor. [Relational]

The process type is considered the major system while the circumstantial is considered the minor system. The circumstantial system is what underlies differences between a simple clause such as 'Diana gave blood', and an expanded clause such as 'Last year, in Geneva, Diana gave blood voluntarily and without pain with her sister at the clinic'. The choice of process involves a particular configuration of participant roles. It is not enough only to describe the process type selected in each clause. Each process is associated with different participant roles, occurring in different configuration.

Figure 1 and 2 below show process types and circumstances.

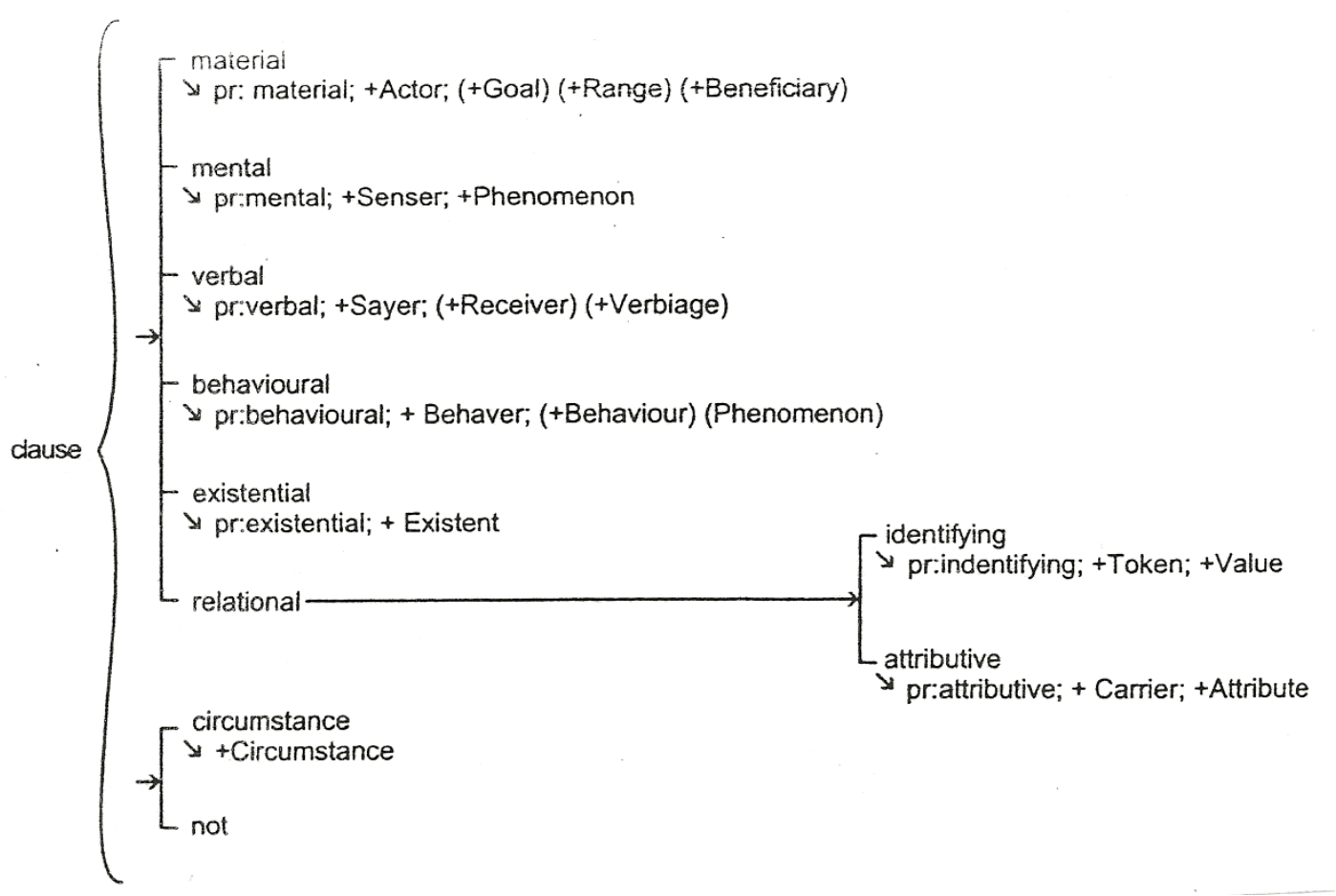

Source: Eggins (2004)

Figure 1. The Process Types and Participants 


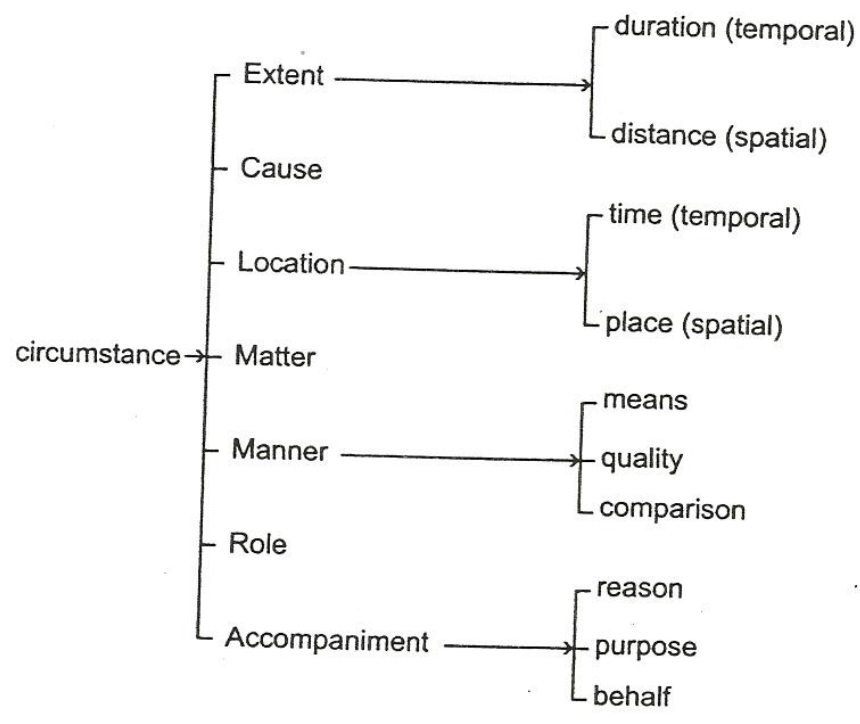

Source: Eggins (2004)

Figure 2. The Circumstances

Eggins (2004) observes that the choice of a material process involves choosing the associated roles of an Actor (obligatory) and optional elements such as a Goal, Range or Beneficiary, whereas the choice of a mental process will involve roles such as Senser and Phenomenon. The choice of a Verbal process involves roles such as Sayer (obligatory), Receiver and Verbiage (optional). Behavioural process requires roles such as Behaver (obligatory), Behaviour and Phenomenon (optional). The choice of existential process involves participant role of Existent while Relational process, which is of two types: (a) identifying and (b) attributive, involves roles such as Token and Value (obligatory) for Identifying, and Carrier and Attribute (obligatory) for Attributive.

In describing the grammar of the clause as representation, Eggins (2004) notes that 'we have not only to describe the differences between process types, but also the associated differences in functional participant roles, and the possible selection of circumstances.

In summary, in analysing transitivity structure in a clause, we are concerned with describing three aspects of the clause:

1) The selection of a process, which is realised in the verbal group of the clause;

2) The selection of participants, which is realised in the nominal groups; and

3) The selection of circumstances, which are realised through adverbial groups or prepositional phrases.

Stated differently, material processes basically involve a participant (the Actor/Agent) doing something to another participant (the Goal/Object). Mental processes involve the human senses-perception, affection, and cognition. Relational processes relate two terms in a variety of ways (similar to how the verb "to be" is used in English). Behavioural processes are expressions of inner workings. Verbal processes make symbolic relationships to be recognized and constructed in human consciousness. With existential processes, phenomena are recognized to exist or to happen.

Halliday (1994) defines the 'goings-on' of life as 'processes' which are represented in the form of language. In terms of traditional grammar, a 'process' can be considered that event or occurrence that results from the use of a verb. The circumstancial options will be used as a framework for the analysis of editorials in this study.

\section{Research Methodology}

This study is both quantitative and qualitative. As a quantitative research, the study has a more logical and data-led approach which provides a measure of data analysis from a statistical and numerical point of view. The study largely uses a method of surveys which are measured in number of frequency and percentages. This made the study flexible and ensures that we have a greater range of reliable data. 
As a qualitative research, the study focused on the ideological opinions expressed in the text through the use of adverbials. This involves examining how people (editors and concerned citizens) feel, what they think and why they make certain choices as certain events unfold.

The research subject for this study is newspaper editorials. The editorials focused on different themes including transportation, education, economy, unemployment, health, legislation and judiciary. Twenty-eight editorials were collected and read. Out of these, only seven were purposively selected for the analysis. Purposive sampling was found appropriate for a qualitative research of this kind, because, apart from saving a lot of time and resources, it made it possible to undertake a safe and systematic selection of samples from a vast array of data.

Each editorial was broken down into clauses. Each sentence is further categorised according to sentence type such as simple, compound and complex sentences. They are also categorised as active and passive sentences. These categorisations enable us to know which sentence or clause can be analysed and which can't be analysed based on the process type, participant and circumstantial options. Only the main clauses in each sentence are analysed.

The selected editorials were read and scrutinized in order to locate the circumstantial options in them. Next, the identified options were categorized. In addition, the contents interpreted by the options were interpreted and related to the ideological opinions expressed in the texts.

\section{Data Analysis and Interpretation}

\subsection{Classification of Circumstantial Options}

Table 1. Circumstantial Options in the Selected Texts

\begin{tabular}{llccccccccc}
\hline S/N & Circumstances & Text 1 & Text 2 & Text 3 & Text 4 & Text 5 & Text 6 & Text 7 & Total & \% 100 \\
\hline 1. & Extent & 01 & 02 & 0 & 05 & 06 & 02 & 06 & 22 & 19.1 \\
2. & Location & 03 & 05 & 04 & 03 & 06 & 02 & 08 & 31 & 26.9 \\
3. & Manner & 03 & 01 & 01 & 02 & 05 & 10 & 04 & 26 & 22.6 \\
4. & Cause & 01 & 03 & 01 & 02 & 03 & 0 & 0 & 10 & 8.6 \\
5. & Accompaniment & 0 & 01 & 02 & 0 & 0 & 02 & 03 & 08 & 6.9 \\
6. & Matter & 01 & 02 & 02 & 03 & 03 & 04 & 01 & 16 & 13.9 \\
7. & Role & 0 & 0 & 0 & 01 & 0 & 01 & 0 & 02 & 1.7 \\
\hline & Total & $\mathbf{0 9}$ & $\mathbf{1 4}$ & $\mathbf{1 0}$ & $\mathbf{1 6}$ & $\mathbf{2 3}$ & $\mathbf{2 1}$ & $\mathbf{2 2}$ & $\mathbf{1 1 5}$ & \\
\hline
\end{tabular}

As the table shows, T5, T7 and T6 (in order of occurrence) have the highest number of circumstances. They are followed by $\mathrm{T} 4, \mathrm{~T} 2, \mathrm{~T} 3$ and $\mathrm{T} 1$.

Location is dominant in all the texts except in T1, T4 and T6, totalling up to 31 occurrences (26.9\%). Manner is also highly used in the texts, especially in T6, T5 and T7 totalling up to 26 occurrences (22.6\%). Extent occurs 22 times (19.1\%), showing that it also plays a significant role in the realisation of the message of the texts. It helps significantly in realising the messages of T5, T7 and T4. Matter and Causes, though not very significant, help in realising the messages of the texts, with Matter having 16 occurrences (13.9\%) and cause $10(8.6 \%)$. Accompaniment and role are sparingly used. Accompaniment occurs 8 times (6.9\%) while role occurs just 2 times $(1.7 \%)$

\subsection{Interpretation of the Content of Circumstantial Options}

\subsubsection{Extent}

Extent is used in some of the texts to tell us HOW certain events took place, as seen in the following examples.

\section{Excerpt 1}

... 1.3 million to 1.9 million $(\mathrm{T} 1, \mathrm{~S} 6)$

In the example above, Extent tells us how annual deaths from road accidents are likely to increase. Extent is also used in some of the texts to tell us HOW LONG certain events took place. Consider the following examples. 


\section{Excerpt 2}

$1 . .$. for so long ... (T2, S17)

2. ... for some months ... (T3, S3)

$3 . .$. to the end ... (T3, S5)

4. ... on a daily basis ... (T4, S4)

$5 . .$. on the increase ... (T4, S13)

6. ... in recent times ... $(\mathrm{T} 4, \mathrm{~S} 19)$

7. ... often times (T6, S11)

8. ... to long imprisonment (T6, S14)

In the first example, Extent helps us to know how long unemployment has been in the country. Examples 2 and 3 give information about how long certain occurrences have been going on in the state. Extent is also used in some of the texts to tell us TO WHAT EXTENT certain events took place. Consider the following examples.

\section{Excerpt 3}

$1 . \ldots$ at all costs ... (T3, S20)

2. ... of 10 percent ... (T7, S12)

3 .... at over $\$ 450$ billion ... (T7, S17)

4 .... as high as 35 percent ... (T7, S21)

\subsubsection{Location}

In the following examples, Location tells us WHEN certain events took place in the selected texts.

\section{Excerpt 1}

1 .... by $2020(\mathrm{~T} 1, \mathrm{~S} 6)$

2. ... in 2007 (T2, S26)

3. ... six years ago $(\mathrm{T} 4, \mathrm{~S} 9)$

4. ... last month $(\mathrm{T} 7, \mathrm{~S} 1)$

$5 . .$. in the first quarter of 2008 (T7, S8)

6. ... last year (T7, S17)

In the following examples, location tells us WHERE certain events took place in the selected texts.

\section{Excerpt 2}

$1 . .$. on the highways (T1, S15)

2. ... on the Ibadan-Ilorin road (T1, S20)

3. ... in Nigeria (T2, S7)

4. ... in many countries (T2, S17)

5 .... from other tertiary institutions (T2, S25)

6. ... in court $(\mathrm{T} 3, \mathrm{~S} 22)$

7. ... in Newspapers (T4, S1)

8 .... in our society $(\mathrm{T} 5, \mathrm{~S} 2)$

$9 . .$. in the universe $(\mathrm{T} 5, \mathrm{~S} 16)$

$10 . .$. the banking halls $(\mathrm{T} 7, \mathrm{~S} 2)$

$11 . .$. in the system $(\mathrm{T} 7, \mathrm{~S} 23)$

\subsubsection{Manner}

In the following examples, Manner tells us HOW (MEANS) certain events took place in some of the selected texts. For example: 


\section{Excerpt 1}

... through road accidents (T1, S19)

Manner also helps to COMPARE EVENTS in order to select the best options for certain events.

\section{Excerpt 2}

1. ... like Rule 15 (T1, S25)

2. ... like malaria, tuberculosis, HIV/AIDS, etc (T1, S9).

In the following examples, manner tells us the FREQUENCY of certain events in some of the selected texts.

\section{Excerpt 3}

1.... daily $(\mathrm{T} 3, \mathrm{~S} 2)$

2. ... profusely $(\mathrm{T} 5, \mathrm{~S} 1)$

3. ... yearly $(\mathrm{T} 5, \mathrm{~S} 9)$

4. ....annually (T5, S16)

$5 . .$. very urgent $(\mathrm{T} 5, \mathrm{~S} 26)$

6. ... systematically (T6, S2)

7. ... consistently $(\mathrm{T} 6, \mathrm{~S} 3)$

8 .... infrequently $(\mathrm{T} 6, \mathrm{~S} 4)$

9. ... dramatically (T6, S12)

$10 . .$. publicly $(\mathrm{T} 6, \mathrm{~S} 13)$

$11 . .$. consequently $(\mathrm{T} 6, \mathrm{~S} 17)$

12. ... particularly $(\mathrm{T} 7, \mathrm{~S} 3)$

$13 . .$. traditionally $(\mathrm{T} 7, \mathrm{~S} 5)$

14. ... understandably (T7, S6)

4.2.4Cause

In the following examples, Cause tells us the REASONS why certain events took place in some of the selected texts.

\section{Excerpt 1}

$1 . \ldots$ in road accidents $(\mathrm{T} 1, \mathrm{~S} 24)$

2.... without knowing $(\mathrm{T} 1,21)$

3. ... for the well-being $(\mathrm{T} 4, \mathrm{~S} 4)$

4. ... thanks to the desperate desires of politicians (T4, S10)

$5 . \ldots$ by the negligence $(\mathrm{T} 5, \mathrm{~S} 2)$

6. ... for us $(\mathrm{T} 5, \mathrm{~S} 4)$

7. ... for this timely intervention (T5, S14)

It also tells us ON WHOSE BEHALF certain events took place in some of the selected texts. For example:

\section{Excerpt 2}

1. ... by the National Directorate of Employment (T2, S26)

Cause also tells us WHY certain steps are taken. For example:

\section{Excerpt 3}

$\ldots$ to free suspects $(\mathrm{T} 3, \mathrm{~S} 23)$

\subsubsection{Accompaniment}

In the following examples, Accompaniment tells us WITH/WITHOUT WHOM/WHAT certain events took place in some of the selected texts.

\section{Excerpt}


1.... without reliable statistics (T2, S19)

$2 . .$. with news of corruption (T3, S1)

3. ... with a minor difference (T3, S5)

4. ... without genuine reasons $(\mathrm{T} 6,12)$

5. ... with smiles (T6, S13)

6. ... with their preferred customers $(\mathrm{T} 7, \mathrm{~S} 1)$

7. ... with some levels of assurance (T7, S5)

8 .... with government's economic policy trust (T7, S13)

4.2.6 Matter

In the following examples, matter tells us ABOUT certain events in some of the selected texts.

\section{Excerpt}

1. ... of the Highway Code (T1, S10)

2. ... of the population (T2, S4)

3. ... of unemployed Nigerians (T2, S3)

4. ... of democratic rule $(\mathrm{T} 3, \mathrm{~S} 10)$

$5 . \ldots$ of Nigerians $(\mathrm{T} 3, \mathrm{~S} 14)$

6. ... in disputes (T4, S4)

7. ... of the people $(\mathrm{T} 4, \mathrm{~S} 5)$

8.... of the Federal Republic of Nigeria (T4, S12)

9 .... of our happiness (T5, S5)

$10 . .$. by nature $(\mathrm{T} 5, \mathrm{~S} 5)$

11.... about this scourge (T5, S11)

12 ... by unnecessary court adjournments (T6, S5)

13. ...by the $\operatorname{EFCC}(\mathrm{T} 6, \mathrm{~S} 11)$

14 .... by the public $(\mathrm{T} 6, \mathrm{~S} 16)$

15. ... of corrupt criminal justice system (T6, S20)

$16 . .$. of the economy $(\mathrm{T} 7, \mathrm{~S} 24)$

\subsubsection{Role}

In the following examples, role gives information about what certain participants appear as.

\section{Excerpt}

... as canonised saints (T6, S9)

\subsection{Discussion of Findings}

From the analysis above, some insights can be gained into the study of editorials. Editorials help to articulate a better understanding of the news media, the unique handling of language and text, and the impact on thought and culture. Some of the issues presented in the news are also represented in editorials. However, editorials have an edge over news report because they develop the story better; they do a research on the story before they publish them; editorials reveal the editors' thoughts or ideas about the story on ground. This latter feature of editorials gives it the ability to articulate a better understanding of the news media. This also enables editorials to have a unique handling of language and text is prominent and significant in this study.

Experiential meaning, of which circumstances is an option, presents us with a number of ways language is used to express meaning in editorials. In this sense, circumstantial options help in the realisation of the messages of the editorials.

The editorials analysed in this study contain contents that capture facts about our social world. Social world in this study include politics, economy, finance, education, security, health, transportation and corruption. All the issues 
raised in all the editorials relate to the ills of the society, or better still, the problems facing Nigeria, created by Nigerians and suffered by Nigerians. For instance, editorials observe that corruption is at the root of many of Nigeria's problems. Corruption takes many forms and infiltrates all political institutions and economic sectors. The ruling government is not performing its functions as promised, and officials are too busy enriching their pockets to govern effectively. The citizens of Nigeria are tired of coming out to cast their votes on election days only to feel their votes haven't been counted. Corruption does not only exist in government, but is pervasive in society. For example, what happens in some companies with male CEOs when a woman applies for a job? Unless they already know them, some of the CEOs demands special and sexual favours from young women seeking employment and at times do not hire them in the end. Those at the top adopt an attitude of 'if I do not already know you, I'm not going to hire you,' and exploit their power - this is just one illustration. Those who do not have connections to top officials or executives remain jobless, even if they are university graduates with top marks. Gender and education will be discussed later, but this is a concrete example of how systemic corruption perpetuates a host of problems in Nigeria.

The Nigerian crime problem gives many citizens in this country sleepless nights. In many places, people feel they can no longer walk around their own neighbourhoods unharmed. Public safety is the most fundamental responsibility of any state, and Nigeria has failed in this regard. Nigeria has a high murder rate. One cause of Nigerian crime is drug trade, in which organised criminal groups in Nigeria are heavily involved. People engage in illegal and bad activities when they are frustrated with legitimate options. Lack of opportunity makes them indulge in criminal acts, and their actions make the whole nation look bad. Instead of allowing persistent unemployment to continue, the government should increase security in the country and hire youths as security agents.

Unemployment is a pressing issue in Nigeria, and many people are frustrated with widespread joblessness. Unemployment in Nigeria is like a disease that the cure is not yet discovered. Students at tertiary educational institutions often graduate into joblessness and low morale. There is a great challenge in Nigeria education. Many Nigerian graduates did not learn good skills during their studies. They were busy reading only textbooks without knowing the applications of what they read. They apply for jobs for which they aren't hired because they lack skills. Graduates often stay in their parents' homes for a long time, with mounting frustration and pessimism. This negativity is one of the major root causes of crime among young people in Nigeria, as they turn to unscrupulous activities because there is nothing else to occupy their time or generate income. There is also a lot of corruption in the Nigerian educational system, particularly universities. Lecturers are known to collect money from students in exchange for good grades. Some say they have to bribe university administrators in order to have their examination results compiled and submitted to the (required) National Youth Service Corps.

Infrastructure is another problem. The power sector is corrupt and mismanaged, and many workers in the electricity sector are not equipped with the proper skills or training. Domestic production suffers in these conditions, but many foreign companies also find it difficult to conduct business in Nigeria because of frequent power failures. This problem keeps Nigeria a Third World country from year to year. Similarly water resources and railways are lacking. Nigeria needs more power and better roads. The environmental and health standards of Nigeria are in a bad state. The health system in Nigeria does not adequately serve the population.

Generally, editorials share a broadly secular, humanist, rationalist view of the world. When the rich for instance, tend to unjustifiably exploit and manipulate the poor, editorials rise up in defence of the latter. The relationship among different members of the society is often monitored by the media and an advocacy role played by editorials to defend the cause of the wretched of the earth. The poor often belong to the unemployed group. They are usually neglected. Consequently, the rate of unemployment continues to rise. Editors, thus employ relational processes to describe the events that unfold in the unemployment circle. They do not exhort the readers to pray for solutions nor to submit to Destiny; they believe in the efficacy of human action. Thus, editorials can be said to share a commitment to national interests and identification with fellow nationals.

Our findings reveal that editorials criticise or attack socio-political, economic and moral dilemmas in the society. Editorials criticise and attack these social ills or vices with a view to proffering a solution to them. By doing this every day, editorials illuminate the day's intelligence. By throwing more light to complex issues of the day, editorials often try to look at the two sides of an issue. They highlight and analyse the strengths and weaknesses of public issues while proffering solutions to complex issues of public concern.

The findings reveal that editors carefully utilise their messages. This is revealed in their use of language, especially in their tone and mood system, this study finds that the use of language is biased. The transitivity system has enabled us to understand how editorials are written by employing certain processes, participants and circumstances which help to critically examine editors' tone and mood as they are expressed in their language. 
A good and powerful editorial usually has impact. In Nigeria for instance, good editorials often galvanise policy formulation on the side of government and relevant stakeholders for the betterment of the society. On the side of the governed, editorials mobilize them either to reject or accept a policy or a burning issue of the day.

Editorials can create a pathway for lawmakers for instance, to initiate bills that would eventually become laws in the nation's statute book. If an editorial is to create impact on its audience, it must reflect the wisdom, integrity and voice of the society.

\section{Conclusion}

The systemic functional linguistic framework adapted for this research made it possible for us to undertake a systematic and detailed text linguistic analysis of the editorials in selected Nigerian newspapers. This research has shown the extent to which SFL examines the ideational features of language manifest in the writings of editors about the neglected, dominated and oppressed groups, on the one hand, and members of the dominant group or perceived oppressors, on the other hand. The editorials selected for analysis in this research exhibit many interesting findings.

The analyses presented here show that SFL provides an analytical framework which is interesting, useful and powerful for the analysis of texts. However, this is not to be understood as being to the exclusion of other possible theoretical approaches, which may well come to similar conclusions. It should be stressed, particularly for readers who are less familiar with SFL, that this approach is not simply a technique of textual analysis, but rather a useful theory of language. As it has been shown in this study, the experiential metafunction in SFL helps highlight the features of the text in a particularly clear, powerful, and objective fashion.

The systemic functional linguistic (SFL) analytical framework made it possible for us to analyse the data linguistically; hence making it possible for the readers of editorials to bring out deeper nuances of meaning than would otherwise have been possible if either perspective had been adopted.

The linguistic analysis of editorials also has pedagogic relevance for students, applied linguistics, text and corpus linguistics. This study attempts to impart to students a sense of the primary purposes of grammar. It is an attempt to counter the prevailing sense of formalism in the study of grammar and promote an approach that not only describes the function and purpose of grammar but also the meaning. It is assumed that students will respond more positively to a focus on meaning rather than on form, because they themselves are more conscious of meaning in their own use of language, especially in its spoken mode. Students and linguists will have the capacity to form and express their own opinion of texts and develop strategies of applying linguistics to the communicative use of language. A good understanding of the corresponding grammatical features of processes can help students use them in expressing their experiences of the world in the appropriate register, and define the syllabuses for students learning English for Specific Purposes (ESP) or Academic Purposes (EAP).

\section{References}

Duyile, D. (2005). Writing For the Media - A Manual for African Journalists. 2nd Edition. Lagos: Gong Communication.

Eggins, S. (2004). An Introduction to Systemic Functional Linguistics, 2nd Edition. London: Continuum International Publishing Group.

Fartousi, H. (2012). A Rhetorical Analysis of a Daily Editorial: 'Wishing Iraq Well'. AASS, 1(2), 197-204.

Flowerdew, J., and Dudley-Evans, T. (2002). Genre Analysis of Editorial Letters to International Journal Contributors. Applied Linguistics, 23(4), 463-489.

Halliday, M. A. K. (1985). An Introduction to Functional Grammar. London: Edward Arnold.

Halliday, M. A. K. (1994). An Introduction to Functional Grammar, 2nd Edition. London: Arnold.

Halliday, M.A.K. (2003). On the "Architecture" of Human Language. In On Language and Linguistics. Volume 3 in the Collected Works of M.A.K. Halliday. Edited by Jonathan Webster.

Halliday, M. A. K., \& Hasan, R. (1976). Cohesion in English London: Longman.

Shokouhi, H., \& Amin, F. (2010). A Systemist "Verb Transitivity: Analysis of the Persian and English Newspaper Editorials. Journal of Language Teaching and Research, 1(4), 387-396.

Thompson, G. (1994). Introducing Functional Grammar. London: Edward Arnold. 